\title{
Gallbadder Volvulus: A Rare Cause of Acute Cholecystitis
}

\author{
Muhammad Imran Aumeerally ${ }^{1,2, *}$ and Francis Asomah ${ }^{1}$ \\ ${ }^{1}$ Department of Surgery, Caboolture Hospital, Caboolture, Queensland, Australia \\ ${ }^{2}$ Ipswich Hospital, Chelmsford Avenue, Ipswich, Queensland, Australia
}

*Corresponding author: Muhammad Imran Aumeerally, Ipswich Hospital, Chelmsford Avenue, Ipswich, Queensland, Australia, Tel: +61408186991; E-mail: imran.aumeerally@gmail.com

Received: 19 Sep, 2019 | Accepted: 01 Oct, 2019 | Published: 07 Oct, 2019

Citation: Aumeerally MI, Asomah F (2019) Gallbadder Volvulus: A Rare Cause of Acute Cholecystitis. J Surg Open Access 5(4): dx.doi. org/10.16966/2470-0991.192

Copyright: (C) 2019 Aumeerally MI, et al. This is an open-access article distributed under the terms of the Creative Commons Attribution License, which permits unrestricted use, distribution, and reproduction in any medium, provided the original author and source are credited.

\section{Abstract}

Gallbladder volvulus is a rare cause of acute cholecystitis and is due to the torsion of the gallbladder along its pedicle. The diagnosis of gallbladder volvulus is often made intra-operatively and therefore failure to recognize the condition pre-operatively may lead to delay in definitive management. This case report presents a 95-year-old female patient admitted to a regional hospital with acute right upper quadrant pain. The patient was taken to theatre and on laparoscopy was found to have a gangrenous gallbladder twisted along its pedicle. A laparoscopic cholecystectomy was performed and the patient was successfully treated. Awareness of this rare entity and prompt surgical intervention is required to limit the potential morbidity and mortality.

Keywords: Gallbladder disease; Torsion; Volvulus; Cholecystectomy; Cholecystitis

\section{Introduction}

Gallbladder volvulus is a rare condition most often seen in elderly patients caused by torsion of the gallbladder along a free mesentery or pedicle. Since first being reported in 1898 by Wendell, approximately 500 cases have been reported in the literature [1]. Gallbladder volvulus presents as gangrenous cholecystitis due to obstruction of the cystic duct and cystic artery. The mainstay of treatment is a cholecystectomy. Given that it is a rare phenomenon, the failure to recognize gallbladder volvulus may lead to delay in diagnosis and treatment, therefore possibly increasing morbidity and mortality. This case report discusses a patient presenting with gallbladder volvulus to a regional hospital.

\section{Case Report}

A 95-year-old female presented with a four-day history of right upper quadrant pain and nausea. She was wheelchair-bound and resided at a high care nursing home due to her significant immobility. She suffered with hypertension, osteoporosis and hearing impairment. She was noted to be on aspirin as primary prevention for vascular disease. Her surgical history was notable for a previous left hip replacement and right knee replacement. She never had any previous abdominal operations.

Her respiratory rate was 24 breaths per minute, her heart rate was 130 beats per minute and her temperature was $38.1^{\circ} \mathrm{C}$. She was significantly tender in the right upper quadrant with guarding. Murphy's sign was present. Blood investigations demonstrated an increased white cell count of $22.3 \times 109 / \mathrm{L}$. Electrolytes, renal function and liver function tests were grossly unremarkable. A CT was initially performed and demonstrated a thickened oedematous gallbladder with a cystic duct to its right side (Figure 1). An ultrasound of the abdomen demonstrated a thickened gallbladder wall with pericholecystic fluid and tenderness on palpation with the probe. A gallstone was not identified. The common bile duct was measured at $6.4 \mathrm{~mm}$. The remainder of the ultrasound study did not demonstrate any notable findings. Chest X-ray demonstrated blunting of the left costophrenic angle.

The patient was initially resuscitated with intravenous fluids and antibiotics. During this time, a medical consult was sought to further assess fitness for theatre given her age and pre-morbid status. The outcome of the medical consult was that the patient likely has mild to moderate valvular heart disease without frank signs of congestive cardiac failure.

After discussion between the treating surgical team and the patient, it was determined that the patient would die without surgical intervention. Consent was obtained to proceed to theatre for a laparoscopic cholecystectomy.

On laparoscopy, a gangrenous gallbladder was identified (Figure 2 ), and it was noted to be twisted around its pedicle. The gallbladder was untwisted and found to be free floating. A laparoscopic cholecystectomy was performed. Intra-operative cholangiogram demonstrated free flow of contrast into the duodenum without a filling defect within the biliary system.

Post-operatively, the recovery of the patient was complicated by runs of atrial fibrillation with rapid ventricular response. The patient was observed in a telemetry bed with consult provided by the medical team and she was successfully treated with amiodarone infusion. 


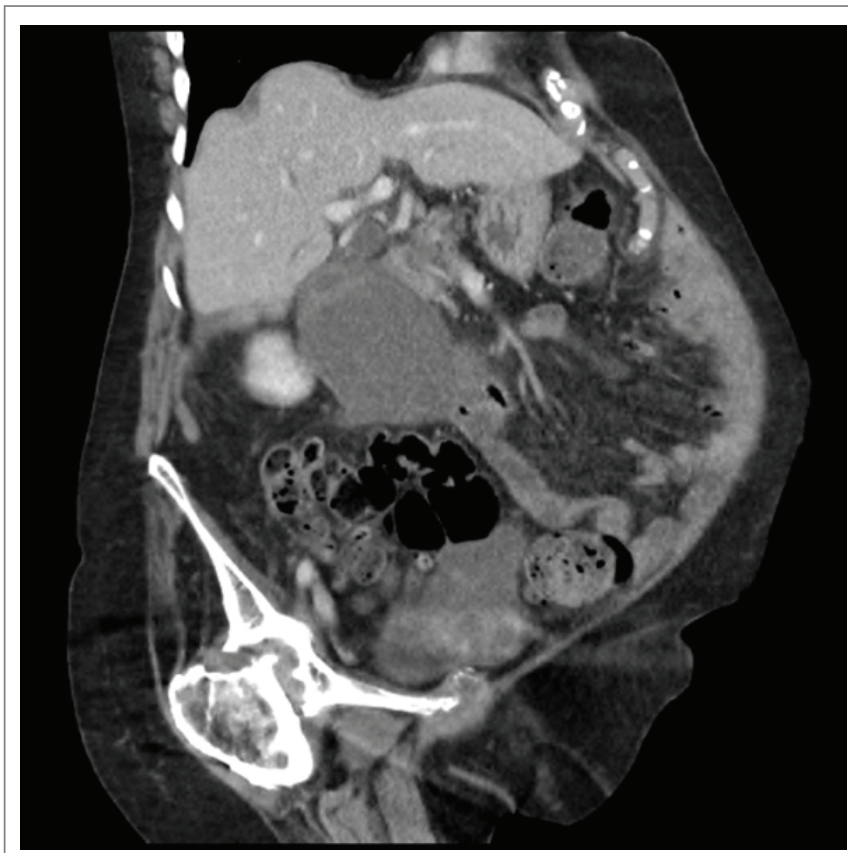

Figure 1: Coronal view of an oedematous gallbladder with a right-sided cystic duct..

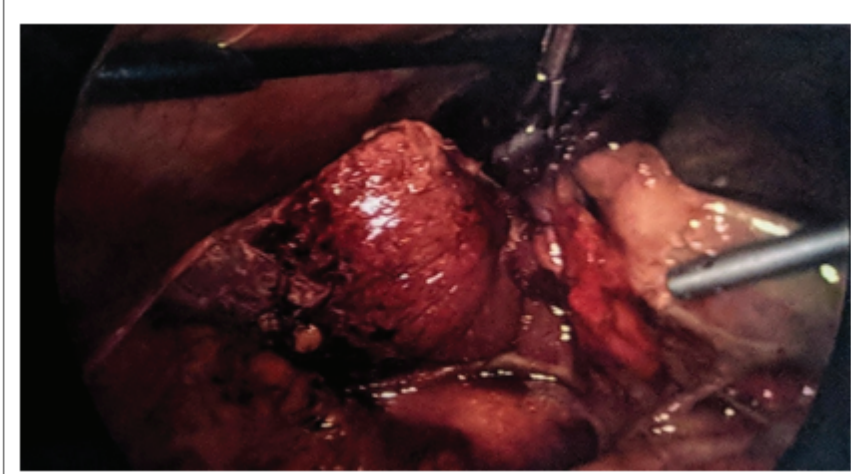

Figure 2: Free-floating and gangrenous gallbladder twisted at its pedicle.

After this period of observation, she was eventually discharged in good health nine days post-operation.

Histopathology reported acute gangrenous cholecystitis and features consistent with clinical history of a volvulus.

\section{Discussion and Conclusion}

Gallbladder volvulus is the torsion of a gallbladder along its mesentery or at its pedicle. This results in obstruction of the cystic artery and duct thus leading to gangrenous cholecystitis.
Gallbladder volvulus is a condition most often seen in elderly patients and has occurrence ratio between women and men of 3:1. Lipoatrophy associated with ageing, liver atrophy and the congenital presence of a long gallbladder mesentery would appear to be associated factors [2]. These factors contribute to a free-floating gallbladder that is mobile and capable of twisting at its pedicle. The presence of gallstones does not seem to impact the likelihood of gallbladder volvulus with $20-30 \%$ of cases reporting cholelithiases [3-5].

The most common presenting is right sided abdominal pain due to an ischaemic gallbladder [6,7]. The pain may be sudden and severe in the case of acute complete torsion or may be colicky in nature in cases of incomplete torsion.

A systemic inflammatory response may not be evident until gangrene and necrosis have set in.

The diagnosis is made more difficult as imaging may not clearly demonstrate the pathology. Classical ultrasound sonography findings may demonstrate a "floating" gallbladder with pericholecystic fluid and wall thickening. Computed tomography may also demonstrate these findings in addition to a cystic artery situated to the right side of the gallbladder or may sometimes demonstrate torsion of the gallbladder along its pedicle. Based on previous case reports, only $9.8 \%$ of gallbladder volvulus cases are diagnosed pre-operatively.

Treatment of a gallbladder volvulus is an emergency cholecystectomy which may be performed as an open procedure or laparoscopically. The diagnosis will often be confirmed intra-operatively. Once recognized and treated promptly with a cholecystectomy, the outcomes are favourable. Therefore, awareness of this condition may lead to a decrease in patient morbidity.

\section{References}

1. Pu TW, Fu CY, Lu HE, Cheng WT (2014) Complete body-neck torsion of the gallbladder: A case report. World J Gastroenterol 20: 1406814072.

2. Mouwad NJ, Crofts B, Streu R, Desrochers R, Kimball BC (2011) Acute gallbladder torsion-a continued pre-operative diagnostic dilemma. World J Emerg Surg.

3. Nakao A, Matsuda T, Funabiki S, Mori T, Koguchi K, et al. (1999) Gallbladder torsion: case report and review of 245 cases reported in the Japanese literature. J Hepatobiliary Pancreat Surg 6: 418-421.

4. Khosraviani K, Thompson NW, Mackle EJ (2000) Volvulus of the gallbladder. Ulster Med J 69: 163-164.

5. Lavy M, Lubrano J, Morati P, Delabrousse E, Idelcadi O, et al. (2010) Gallbladder volvulus diagnosed at computed tomography. Am Surg 76: 1302-1303.

6. Du Rieu MC, Carrère N (2012) Gallbladder volvulus. J Visc Surg 149: 172-173.

7. DeBoard ZM, Ferrigno L, Thoman D (2015) Gallbadder Volvulus: A Single Institution's Experience over Two Years. Am Surg 81: E347-E348. 